\title{
Educação empreendedora: um estudo bibliométrico sobre a produção científica recente
}

\author{
Denise Adriana Johan Bacharel em Economia. Universidade Regional do Noroeste do Estado do Rio Grande do Sul \\ (UNIJUI) - Brasil.denisejohann@gmail.com \\ Cristiane Krüger Doutoranda em Administração. Universidade Federal de Santa Maria (UFSM) - Brasil. \\ cris.kruger@hotmail.com \\ Italo Fernando Minello Doutor em Administração. Universidade Federal de Santa Maria (UFSM) - Brasil. \\ ifminello@gmail.com
}

\section{RESUMO}

O objetivo deste estudo é apresentar o cenário das pesquisas na área de educação empreendedora na base de dados Web of Science, incluindo a caracterização da produção, dos aspectos metodológicos e dos temas correlatos. O trabalho descritivo e quantitativo, de natureza bibliométrica, busca levantar as características da produção acadêmica. Para tanto, foi realizada uma pesquisa bibliométrica, na qual foram investigados 2.474 artigos publicados no período de 2008 a 2017, na respectiva base de dados, incluindo a caracterização da produção, dos aspectos metodológicos e dos temas correlatos. Inicialmente, foi identificado o total de publicações, sendo caracterizado por suas áreas temáticas, tipos de documentos, ano das publicações, autores, agências financiadoras e instituições, países, idiomas e, por fim, foi analisado o índice $h-b$ e o índice $m$. A educação empreendedora nesta pesquisa apresenta-se como uma importante ferramenta para a disseminação do empreendedorismo, sendo o último considerado um dos responsáveis pelo desenvolvimento econômico e social. O estudo também evidencia a necessidade de maior incentivo para que se proporcione mais pesquisas e estudos sobre educação empreendedora no Brasil. No decorrer do trabalho percebeu-se a importância de mecanismos de busca como o Web of Science, que servem de ferramenta para que a comunidade acadêmica tenha acesso às publicações, assim como se busque demais informações a respeito da evolução dos temas de interesse.

Palavras-chave: Educação Empreendedora. Bibliometria. Empreendedorismo. Administração.

\section{Entrepreneurial education: a bibliometric study on recent scientific production}

\begin{abstract}
The purpose of this study is to present the research scenario in the area of entrepreneurial education in the Web of Science database, including the characterization of production, methodological aspects and related themes. The descriptive and quantitative work, of bibliometric nature, seeks to raise the characteristics of the academic production. For that purpose, a bibliometric survey was carried out, in which 2,474 papers published in the period from 2008 to 2017 were investigated in the respective database, including the characterization of production, methodological aspects and related themes. Initially, the total number of publications was identified, being characterized by its thematic areas, document types, year of publications, authors, funding agencies and institutions, countries, languages and, finally, the $h-b$ index and the $m$ index were analyzed. Entrepreneurial education in this research presents itself as an important tool for the dissemination of entrepreneurship, which is considered one of the propellers of economic and social development. The study also highlights the need for greater incentive to provide more research and studies on entrepreneurial education in Brazil. In the course of the study, the importance of search engines such as the Web of Science, which serve as a tool for the academic community to access publications, as well as the search for other information about the evolution of the topics of interest, was perceived.
\end{abstract}

Keywords: Entrepreneurial Education. Bibliometrics. Entrepreneurship. Management. 


\section{INTRODUÇÃO}

A partir da essência de fomentar o espírito empreendedor aliada à premissa de que o empreendedor não necessariamente seja definido como um empresário, mas nas mais diversas formas de empreender, aplicadas dentro ou fora das organizações, se elenca a educação empreendedora como uma forma de desenvolver o indivíduo em toda a sua amplitude. Para Schaefer e Minello (2017), o indivíduo empreendedor é o ator capaz de inovar no processo evolutivo do mundo contemporâneo, capaz de resolver problemas e absorver oportunidades, atribuindo-se este sujeito como agente de mudança. A compreensão de empreendedorismo por meio de diversas pesquisas vem caracterizando-o não somente como uma forma de saber, mas também como uma forma de ser (SCHAEFER; MINELLO, 2017).

Como refere Volkmann (2004) a educação para o empreendedorismo é importante para a saúde de qualquer universidade e para a economia do próprio país. Para efeitos desta pesquisa, educação empreendedora compreende conhecimento, comportamento e aprendizagem por meio de um processo dinâmico de conscientização, associação e aplicação em que o empreendedor vivencia de forma prática, podendo transformar seu conhecimento e experiências em resultados. Isso porque a experiência empreendedora é aquela vivenciada pelo empreendedor, constituída pela observação direta e pela participação em eventos associados à atividade empreendedora, como por exemplo a criação de um novo projeto ou empreendimento. Já o conhecimento empreendedor é o resultado prático e recolhido dessa experiência empreendedora, ou seja, o conhecimento adquirido de forma experiencial (POLITIS, 2005).

A temática educação empreendedora não só no Brasil, mas em diversos países do mundo, tem sido reconhecida por sua importância no desenvolvimento, seja econômico ou social, tendo sido acrescentada nas agendas e debates políticos, econômicos e acadêmicos das Nações Unidas (UNCTAD, 2015; LIMA et al., 2015a). Tavares, Moura e Alves (2013) salientam que é necessário o envolvimento em ambientes de aprendizagem para o desenvolvimento do empreendedor, possibilitando desta forma, o aprimoramento de características e aptidões para o seu crescimento. A relação entre estes constructos, conhecimento, comportamento e aprendizagem, forma o empreendedor (DOLABELA, 2008). Para Schaefer e Minello (2016), os estudos sobre empreendedorismo avançaram nas últimas décadas, mas o tema educação empreendedora ainda necessita de estudos e discussões mais consistentes para que haja uma disseminação maior e mais eficaz.

Diante de tal problemática, o objetivo deste estudo é apresentar o cenário das pesquisas na área de educação empreendedora na base de dados Web of Science, incluindo a caracterização da produção, dos aspectos metodológicos e dos temas correlatos. Para alcançar tal objetivo, incialmente, realizou-se a consulta do termo educação empreendedora na base, verificando-se mais de duas mil publicações no período total disponível. Por conseguinte, definiu-se o período de 2008 a 2017 para a presente pesquisa, tendo em vista a maior disponibilização de artigos científicos em modo digital se concentrar nos últimos anos.

Nessa pesquisa a análise da produção científica foi realizada no âmbito da produção individual de cada autor. $O$ estudo preocupa-se também com os aspectos bibliométricos relacionados com a produtividade dos autores, o grau de concentração da pesquisa acadêmica em educação empreendedora, temáticas correlacionadas, nacionalidades e idiomas das publicações, dentre outros.

$\mathrm{O}$ artigo prossegue com a apresentação do referencial e os procedimentos metodológicos, os quais incluem os modelos estatístico e bibliométrico utilizados e uma análise por meio do mapa textual de palavraschaves e cocitações. Na sequência, os resultados obtidos são discutidos. Por fim, são apresentadas as considerações finais contemplando contribuições, limitações e sugestões para futuras pesquisas.

\section{EDUCAÇÃOEMPREENDEDORA: CONCEITOS E PERSPECTIVAS}

Desde os anos de 1900, o empreendedorismo tem se destacado, a partir dos trabalhos de Schumpeter (1985), sob um enfoque econômico. Já, nos anos 2000, apresentou-se uma necessidade ligada à figura do indivíduo empreendedor e verificou-se pesquisas voltadas ao ensino do empreendedorismo bem como a inclusão e evolução dos cursos de empreendedorismo (KLEIN; BULLOCK, 2006; KATZ, 2003). 
Sobre o conceito de empreendedorismo, o desenvolvimento do tema acompanha a evolução histórica do papel do empreendedor. Inicia-se com o conceito de empreender que é, segundo Schumpeter (1985), inovar a ponto de criar condições para uma radical transformação de um determinado setor, ramo de atividade, território, na qual o empreendedor atua. Para Schumpeter (1985), o empreendedor é aquele que realiza novas combinações dos meios produtivos, capazes de propiciar desenvolvimento econômico, quais sejam: introdução de um novo bem, introdução de um novo método de produção, abertura de um novo mercado, conquista de uma nova fonte de oferta de matérias-primas ou bens semimanufaturados, constituição ou fragmentação de posição de monopólio.

Diversos autores ao longo do tempo têm estudado e contribuído para a definição de empreendedorismo, neste sentido, no GEM (2015) relaciona-se ao empreendedorismo o desenvolvimento social e econômico do País. Segundo Drucker (1996) empreendedorismo é uma disciplina que pode ser ensinada e aprendida, levando conhecimento de como e onde o empreendedor pode obter sucesso. Já, para Dornelas (2008) empreendedorismo é tido como o envolvimento de pessoas e processos que, em conjunto, levam à transformação de ideias em oportunidades e criação de negócios de sucesso. McClelland (1987) realizou estudos abordando o empreendedorismo sob o aspecto comportamental, considera o empreendedor como aquele que busca por realização (Teoria das Necessidades). Nessa linha, Portela et al. (2008) salientam que o empreendedorismo não surge apenas por oportunidade, ocorre também por outros fatores, como desemprego e emprego precário, ou seja, pela necessidade.

Para Filion (1999) o empreendedor é criativo, tem capacidade de estabelecer e atingir objetivos com inovação e visão, detectando oportunidades e criação ou melhorias em algo já existente ou uma necessidade observada. Sob esse aspecto ação é fundamental, os empreendedores, para Dolabela e Filion (2013), são orientados para a agir. De acordo com Veiga (2006), ser um empreendedor é uma forma estratégica de contribuir para o crescimento econômico e obter sucesso no mercado.

Além destes, Tavares, Moura e Alves (2013) compreendem empreendedorismo como a caracterização de uma atividade realizada por um indivíduo inovador, perceptível às oportunidades do mercado, disposto a lançar novos negócios, produtos ou serviços. Gerber (2004), afirma que o empreendedor além de ser uma pessoa adepta à mudança, é visionária e sonhadora, criativa, que cria probabilidade dentre possibilidades, transformand o o caos em harmonia. O autor descreve o empreendedor como um inovador, com características próprias, combinando criatividade e inovação, criando diferentes ofertas para adaptar, abrir ou desenvolver novos espaços em novos mercados.

O empreendedor, em qualquer área, é aquele que almeja transformar sonho em realidade, podendo modificar a realidade em que vive (DOLABELA, 2006). Ser empreendedor não é somente acumular conhecimentos, mas possuir atitudes, comportamentos, formas de percepção do mundo e de si mesmo, é voltar-se para atividades em que o risco e a capacidade de inovar, de ser perseverante e de conviver com a incerteza (DOLABELA, 2008). Desta forma, destaca-se a importância no ensino do empreendedorismo, bem como sua contribuição para o desenvolvimento da cultura empreendedora na sociedade. Salienta-se que a educação empreendedora além de incentivar o comportamento empreendedor capacitando o aluno para o mercado de trabalho também amplia as formas de encarar um negócio próprio, atendendo uma demanda já existente ou estruturando um novo negócio com melhorias no serviço já oferecido (KRAKAUER et al., 2015).

Dada relevância ao empreendedorismo e considerando uma possibilidade para o desenvolvimento social e econômico, passou a estudar-se não somente o fenômeno empreender, mas também a educação empreendedora, bem como sua prática e implantação em sala de aula (BAKAR; ISLAM; LEE, 2015). A educação empreendedora viabiliza ao estudante enxergar e avaliar determinada situação, assumindo uma posição proativa frente a ela, fornecendo condições a busca de oportunidades, capacitando-o a elaborar e planejar formas e estratégias de interagir com aquilo que ele passou a perceber (LOPES, 2014; SOUZA et al., 2006).

Os estudos de Lima et al. (2015) revelaram que esta educação tem uma relação positiva com a intenção de empreender. A identificação do estudo de Lima et al. (2015) foi realizada por meio do instrumento de coleta de dados do estudo GUESS internacional. Como resultado do estudo, concluiu-se que a educação empreendedora é uma alavanca no processo de empreender. Para os autores, a educação empreendedora beneficia não somente os estudantes que pretendem abrir seu próprio negócio, vai além do desenvolvimento 
de conhecimentos e desenvolvimento de habilidades comportamentais empreendedoras, impactando no desenvolvimento do pensamento criativo, crescimento de autoestima, reponsabilidade e geração de inovações.

Zampier e Takahashi (2014) acrescentam que um comportamento empreendedor pode ser aperfeiçoado, aliado ao processo de educação empreendedora, evidenciando a importância de tal educação para o desenvolvimento e propagação desta. Para isto, os autores destacam a importância da educação empreendedora neste processo, não somente frente a iniciativas de negócios, mas também em seus postos de trabalho, onde estão inseridos, seja na universidade ou no trabalho, enfim, gerando inovação ou explorando necessidades que o mercado apresente, promovendo o desenvolvimento do empreendedorismo.

Segundo Tavares, Moura e Alves (2013) são várias as definições e atribuições relacionadas ao indivíduo empreendedor, havendo algumas lacunas ainda a serem estudadas dada a complexidade do tema, desta forma, conceituar empreendedorismo torna-se uma tarefa complexa e um grande desafio aos estudiosos da área. Educação empreendedora para os autores refere-se ao preparo dos jovens para seu desenvolvimento social, fortalecendo seu projeto de vida, desenvolvendo suas habilidades e competências para poder decidir seu futuro.

Diante disso, pode se entender a educação empreendedora como um processo dinâmico atrelado as mais diversas conjunturas, podendo assim ser considerado uma forma estratégica de contribuir para o crescimento econômico e social de um país, de uma organização ou de um mercado em específico.

Corroborando com Lima et al. (2014), os estudos de Fayolle e Gailly (2015), observaram o impacto da ação empreendedora nas atitudes e intenções empreendedoras frente ao empreendedorismo e revelaram que a educação empreendedora se mostra de maior forma positiva a medida de pouco ou inexistente contato anterior com formas de empreender, ao mesmo tempo que os participantes que já haviam tido contato com o empreendedorismo não tiveram impactos significativos. Conforme estudos de Handrimurtjahjo, Setiadi e Kuncoro (2015) os estudantes estão cientes da atitude e intenção empreendedoras como fatores determinantes do sucesso empresarial, com ligação direta nas competências e qualidades, estes compreendem que atitudes empreendedoras levam à construção de intenções empreendedoras.

A Comissão Europeia (2012) apoia e reconhece a relevância de programas de formação empreendedora, dando suma importância ao desenvolvimento, estímulo e prática de educação voltada ao empreendedorismo. Diante disto, sinaliza-se países como Espanha, Irlanda, Chipre, Polônia e Reino Unido que contemplam o empreendedorismo em seus currículos escolares de ensino básico. A Comissão Europeia estabeleceu diretrizes estratégicas em 2012, como o avanço do perfil empreendedor por meio da educação, sendo uma das principais ações para a promover a atividade empreendedora, bem como o avanço do perfil empreendedor do bloco, no qual aos estados-membros é dada a recomendação, como a promoção de competências empresariais por meio de maneiras criativas de ensinar e aprender. Todos os jovens devem beneficiar pelo menos uma experiência empresarial prática antes de deixar o ensino obrigatório (EUROPEAN COMMISSION, 2008).

Uma relação entre os três objetivos para a educação empreendedora no ensino superior foi desenvolvida pela Comissão Europeia (2008), sendo: (a) desenvolver espírito empreendedor entre os estudantes, (b) treinar estudantes para abrir um negócio e administrá-lo, (c) desenvolver habilidade empreendedoras necessárias para identificar e explorar oportunidades de negócios. Essa relação é demonstrada na Figura 1. 
Figura 1 - Objetivos da Educação Empreendedora

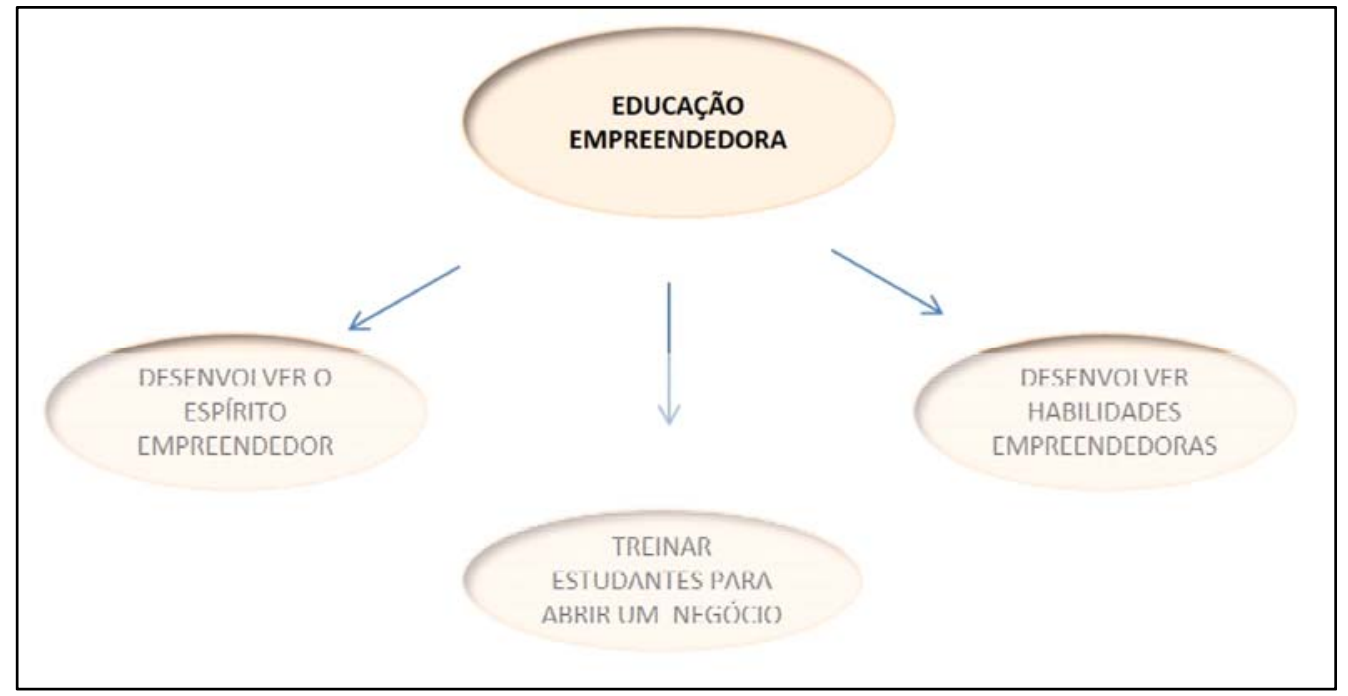

Fonte: Baseado na proposta da European Commission Enterprise and Industry Directorate-General (2008).

A necessidade de promover o crescimento e desenvolvimento é amplamente reconhecida. Neste contexto, observa-se que alguns dos componentes necessários para o crescimento são a criação de riqueza por meio das organizações nos setores da economia em todas as esferas indústrias, comércios e serviços, bem como indivíduos empreendedores e proativos. Atualmente, é consenso que o empreendedorismo é fundamental para o crescimento econômico e geração de riqueza, promovendo desta forma a geração de renda e emprego da população (GEM, 2010). Neste contexto, a educação empreendedora pode agir como propulsora do empreendedorismo.

Nessa perspectiva, Gomes e Silva (2018) destacam que após muitos estudos há um consenso de que a maneira mais eficiente para o empreendedorismo ser ensinado é por meio de uma realidade vivenciada, por meio de uma educação empreendedora dinâmica que aplique o conteúdo teórico com base em fatos e exemplos do mundo real dos negócios e organizações. Nessa linha de raciocínio, os autores ressaltam a importância da educação empreendedora não somente como uma disciplina curricular em todos as esferas, da educação básica ao ensino superior, mas que o empreendedorismo seja ensinado pelos docentes de forma atrativa por meio de metodologias próprias e dinâmicas.

\subsection{Estudos recentes sobre Educação Empreendedora}

Por meio da revisão bibliográfica foi possível explorar estudos recentes que abordam a temática educação empreendedora, revelam o seu caráter emergente, e o que se tem pesquisado a respeito de tal temática.

Tavares, Moura e Alves (2013), analisaram a importância da educação empreendedora para a geração de um ambiente empreendedor e a formação de novos negócios. Os autores realizaram uma pesquisa bibliográfica. A partir dos estudos analisados, pôde-se observar que o empreendedorismo é um importante fator para o desenvolvimento e geração de riqueza das regiões. Percebe-se que regiões com maior nível de empreendedorismo, destacam-se na geração de negócios inovadores, tornando-a mais dinâmica e desenvolvida. Além disso, verificou-se que regiões que investiram na educação empreendedora de crianças e jovens, conseguiram um desenvolvimento superior. Estas constatações demonstram a importância dos governos e instituições de ensino realizarem investimentos na formação empreendedora da população para a geração de um ambiente propício a formação de negócios inovadores.

Vieira et al. (2014), buscaram comparar os resultados obtidos pelo Estudo GUESS Brasil com um levantamento realizado junto aos discentes do Curso de Administração da Universidade Estadual de Londrina - UEL. Para isso, os autores realizaram uma pesquisa com 251 (44,19\%) estudantes. A análise dos dados 
reproduziu as variáveis do Estudo GUESS Brasil, apresentando o perfil dos universitários, o contexto da IES, as intenções de carreira e motivações profissionais, a importância da opinião de pessoas próximas nas tomadas de decisões dos discentes, as informações sobre o negócio que os universitários pretendem iniciar e, por fim, o cálculo do índice de empreendedorismo. Verificou-se, que diminui a intenção de trabalhar como funcionário em uma empresa (seja ela pequena, média ou grande) e cresce, particularmente entre os alunos de Administração, a porcentagem dos que pretendem trabalhar no serviço público e, ainda mais fortemente, o intuito de ser dono do próprio negócio, seja fundando a própria empresa, uma franquia ou adquirindo uma empresa não controlada pela família. A maior motivação para escolher a carreira ou o trabalho futuro está ligada às questões relativas à realização de um sonho pessoal de crescimento e aprendizagem, seguida pelas opções financeiras. É possível concluir que os estudantes pesquisados apresentam fortes características empreendedoras, mas que há algumas barreiras para a aplicação dessas características, principalmente no que tange à falta de possibilidades e acesso ao capital financeiro.

Silva e Pena (2017) objetivaram identificar os principais métodos e práticas de ensino adequados à educação empreendedora, conceitos e características do tema a partir de revisão da literatura. Segundo o estudo, a educação empreendedora tem como finalidade preparar empreendedores com conhecimentos, habilidades e competências para defrontarem os desafios de criação, condução e expansão de negócios. Outro ponto elencado diz respeito à importância de ensinar de modo diferente ao da educação tradicional para o desenvolvimento efetivo de tais habilidades, devendo a educação empreendedora combinar aulas teóricas e atividades práticas, de modo a estimular a inovação, criatividade, reflexões e ações que desenvolvam habilidades críticas, sociais e de liderança nos estudantes.

O trabalho de Gomes e Silva (2018), diagnosticou e analisou a percepção dos alunos em relação às suas experiências no Instituto Federal de Educação Ciência e Tecnologia do Rio Grande do Norte (IFRN), com a disciplina Gestão Organizacional. Os autores verificaram como um método de ensino denominado educação empreendedora pode disseminar assuntos inerentes ao mercado de trabalho e a criação de empresas, de forma dinâmica e eficiente. O estudo teve como objetivo analisar a percepção dos alunos concluintes, nos anos 2012 a 2014, dos cursos técnicos integrados de nível médio do IFRN - Campus Currais Novos - em relação às suas experiências nesta instituição de ensino, em particular, com a disciplina Gestão Organizacional, ministrada com base em uma educação empreendedora. Os resultados indicaram que as experiências na instituição bem como a didática utilizada na disciplina foram positivas. Os alunos pesquisados consideraram satisfatória a disciplina ministrada, bem como a didática utilizada pelo docente, isto é, compreendem como instigante e proveitoso o estudo relacionado ao empreendedorismo, principalmente quando baseado em uma educação empreendedora. Além disso, os alunos perceberam que podem fazer a diferença em suas vidas como protagonistas, mesmo se tornando empreendedores jovens. Apesar da pouca experiência de vida, podem dar passos sozinhos.

Atualmente, a partir dos estudos acerca da educação empreendedora, verifica-se que o empreendedor não pode ser apenas entendido como um indivíduo que nasce com vocação para empreender, mas como alguém que possui um conjunto de características que o levam a ser empreendedor. Estas características podem ser desenvolvidas em qualquer indivíduo. A formação de empreendedores torna-se um importante fator para o desenvolvimento econômico de uma região, tornando-a atrativa de negócios inovadores e formadora de capital social com elevado nível de conhecimento. Observa-se a necessidade das organizações governamentais e das instituições de ensino aterem-se à necessidade de contemplar a educação empreendedora na formação das crianças e jovens, estabelecendo assim um ambiente propício ao desenvolvimento do empreendedorismo.

Além dos estudos apresentados que dão suporte para o estudo, cabe salientar que existem outros estudos na literatura que se destacam na área da Administração. Cita-se o estudo de Moreira, Moreira, Silva (2014) em que foi realizada uma análise sobre a produção científica nas áreas de empreendedorismo e comportamento empreendedor, uma classificação e análise estatística de obras citadas nas referências bibliográficas ou citações utilizadas pelos autores, particularmente com o confronto destas informações com a Lei de Lotka (LL), que é um princípio que estuda sobre a produtividade dos autores de um determinado campo científico. Esta lei da produtividade parte da premissa de que, proporcionalmente, poucos autores 
publicam mais (e são mais citados) do que muitos autores, que publicam menos. Esta distribuição é verificada em campos avançados da ciência. Moretti e Campanário (2009) salientam que essa lei tem a seguinte definição: para estabelecer a parte com que homens de diferentes qualidades contribuem ao progresso da ciência, a lei estabelece os fundamentos do quadrado inverso, afirmando que o número de autores que fazem ' $n$ ' contribuições em um determinado campo científico é aproximadamente $1 / \mathrm{n}^{2}$ daqueles que fazem uma só contribuição. A proporção daqueles que fazem uma única contribuição é de mais ou menos $60 \%$.

\section{PROCEDIMENTOS METODOLÓGICOS}

Nesta seção são contemplados os procedimentos metodológicos adotados para satisfazer o problema de pesquisa levantado.

\subsection{Tipo de pesquisa}

O presente estudo foi desenvolvido a partir de uma pesquisa bibliométrica, classifica-se como descritiva de natureza empírica e de cunho quantitativo (HAIR, 2005). Por meio da bibliometria é possível identificar e analisar as motivações que levam um dado pesquisador a investigar um determinado assunto, a rede de relacionamento que há entre os pesquisadores, o que se tem publicado a respeito de um determinado tema, quais os principais assuntos com os quais os estudos têm relacionado o tema, dentre outros fatores (BELFORT; FREITAS; MARTENS, 2015).

A pesquisa quantitativa para Richardson (2011) trabalha com amostras mais amplas, fornecendo dados mais precisos em relação ao problema a ser estudado, sendo indicada quando já se tem mais informações sobre o mesmo. Além disso, para Roesch (2005) este tipo de pesquisa tem por finalidade obter informações sobre determinada população de forma objetiva. Já, a pesquisa descritiva, para Triviños (2008), descrever as características de determinadas populações ou fenômenos, utilizando-se de técnicas padronizadas de coleta de dados, procurando relações entre as variáveis. Para Klein, Silva e Machado (2015) tais pesquisas têm por finalidade descrever ou traçar informações sobre um assunto em particular.

\subsection{Definição da amostra}

Os dados para realização desta pesquisa foram coletados por meio da base Web of Science do Institute for Scientific Information (ISI). Segundo Franceschet (2010) o ISI foi fundado por Eugene Garfield em 1960 e adquirido pela Thomson (hoje Thompson Reuters) em 1992, e consiste em uma das maiores companhias do mundo da informação.

A Web of Science consiste em uma base multidisciplinar que indexa somente os periódicos mais citados em suas respectivas áreas. É também um índice de citações na web, na qual além de identificar as citações recebidas, referências utilizadas e registros relacionados, se pode analisar a produção científica com cálculo de índices bibliométricos e o percentual de autocitações, assim como a criação de rankings por inúmeros parâmetros.

A base possui atualmente mais de 9.000 periódicos indexados (CAPES, 2015), a partir de 2012 o conteúdo foi ampliado com a inclusão do Conference Proceedings Citation Index- Science (CPCI-S); Conference Proceedings Citation Index-Social Science \& Humanities (CPCI-SSH). As referências de todos os itens indexados são extraídas e a interface das referências citadas lista todas as citações de trabalhos às obras de um autor, independentemente dos itens citados serem indexados pela Web of Science ou não (BAR-ILAN, 2008). 


\subsection{Coleta de dados}

A coleta de dados foi realizada a partir do mecanismo de busca da Web of Science, utilizando como palavras-chaves, entrepreneurial education e entrepreneurship, e delimitando a busca para o período de 2008 a 2017 (10 anos), em que foram buscadas as publicações para análise.

A pesquisa dividiu-se em quatro etapas (Figura 2). Primeiramente digitou-se as palavras entrepreneurial education, dessa forma, foram levantadas as informações: número total de publicações, áreas temáticas, tipo de documentos, ano das publicações, autores, título das fontes, instituições, agências financiadoras, países e idiomas. Na segunda etapa foram identificados os tópicos a serem combinados com os tópicos entrepreneurial education e entrepreneurship. A partir de uma breve análise das publicações encontradas na primeira etapa foram enumerados vinte tópicos a serem combinados com o termo entrepreneurial education e entrepreneurship. Na terceira etapa, ocorreu a segunda busca ao sistema, combinando cada um dos tópicos relacionados com o termo entrepreneurial education no mesmo período de dez anos (2008 a 2017). Em seguida, na quarta etapa, realizou-se a classificação das publicações, foram identificados os hot topics por meio do cálculo do índice h-b e m.

Figura 2 - Etapas da Pesquisa

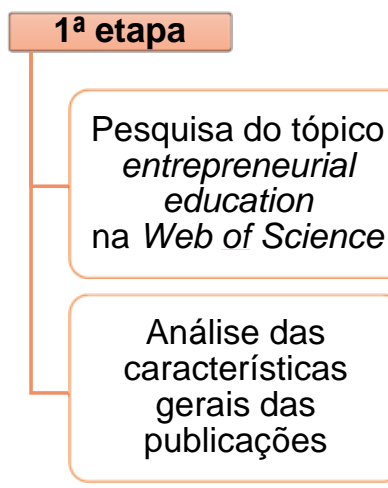

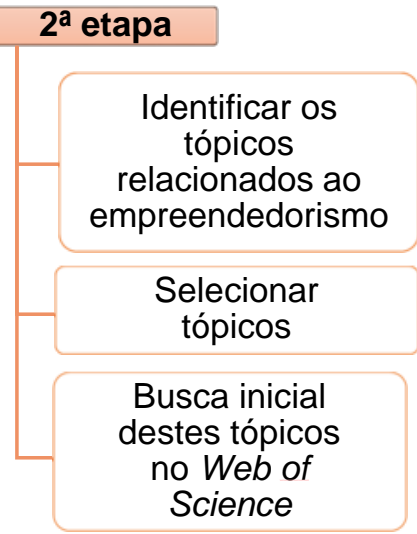
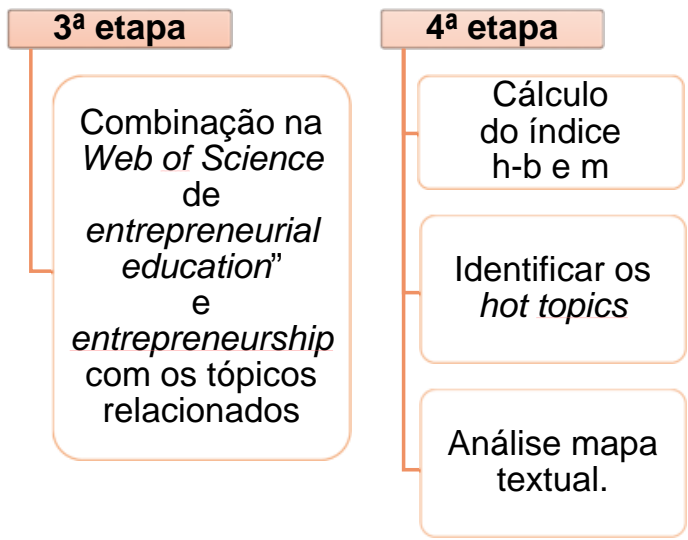

Fonte: elaborado pelos autores (2018).

Por fim foi realizada uma análise por meio de mapa textual gerado a partir do software VOSViewer. Essa ferramenta é gratuita e permite que seus usuários criem e visualizem redes bibliométricas, neste sentido foram imputados os dados pertinentes à pesquisa realizada no Web of Science.

De acordo com as etapas evidenciadas na Figura 2 foi realizada a análise bibliométrica do respectivo estudo, apresentada a seguir.

\subsection{Modelo Conceitual}

A análise bibliométrica do estudo buscou identificar as categorias de análise dispostas na Quadro 1.

Quadro 1 - Modelo conceitual

\begin{tabular}{|c|c|}
\hline $\begin{array}{c}\text { Caraterísticas gerais das } \\
\text { publicações }\end{array}$ & $\begin{array}{c}\text { Número de citações de cada } \\
\text { publicação }\end{array}$ \\
\hline Total de publicações & Índice $\mathrm{h}-\mathrm{b}$ \\
\hline Áreas temáticas & Índice $\mathrm{m}$ \\
\hline Tipos de documentos & \\
\hline Ano das publicações & \\
\hline Autores & \\
\hline Instituições & \\
\hline
\end{tabular}




\begin{tabular}{|c|l|}
\hline Agências financiadoras & \\
\hline Países & \\
\hline Idiomas & \\
\hline
\end{tabular}

Fonte: elaborado pelos autores (2018).

O h-index (índice-h) foi proposto por Hirsch (2005) em sua pesquisa denominada An index to quantify an individual's scientific research output como forma de caracterizar a produção científica de um pesquisador. Hirsch (2005) parte do princípio de que, a quantificação do impacto e a relevância da produção científica individual são muitas vezes necessárias para a avaliação de pesquisadores e comparação de propósitos. Posteriormente, Banks (2006) propôs o índice h-b uma extensão do h-index, que é obtido por meio do número de citações de um tópico ou combinação em determinado período, listados em ordem decrescente de citações. O índice h-b é encontrado em publicações que tenham obtido um número de citações igual ou maior a sua posição no ranking. Banks (2006) também explica o cálculo do índice $\mathrm{m}$, o qual é obtido por meio da divisão do índice $h-b$ pelo período de anos que se deseja obter informações (n). Para a análise dos índices dos índices h-b e m foram utilizadas as definições de Banks (2010) evidenciadas no Quadro 2.

Quadro 2 - Definições para classificação de hot topics

\begin{tabular}{|c|l|}
\hline Índice $\mathbf{m}$ & \multicolumn{1}{c|}{ Tópico } \\
\hline $\mathbf{0}<\mathbf{m} \leq \mathbf{0 , 5}$ & $\begin{array}{l}\text { Pode ser de interesse para pesquisadores em um campo específico de pesquisa, o qual engloba } \\
\text { uma comunidade pequena. }\end{array}$ \\
\hline $\mathbf{0 , 5}<\mathbf{m} \leq \mathbf{2}$ & $\begin{array}{l}\text { Provavelmente pode se tornar um hot topic como área de pesquisa, no qual a comunidade é } \\
\text { muito grande ou o tópico/combinação apresenta características muito interessantes. }\end{array}$ \\
\hline $\mathbf{m}>\mathbf{2}$ & $\begin{array}{l}\text { É considerado um hot topic, tópico exclusivo com alcance não apenas na sua própria área de } \\
\text { pesquisa e é provável que tenha efeitos de aplicação ou características únicas. }\end{array}$ \\
\hline
\end{tabular}

Fonte: Banks (2010).

A partir das definições de Banks (2010) neste estudo serão considerados como hot topics os tópicos com índice $m>2$.

\section{CARACTERÍSTICAS GERAIS DAS PUBLICAÇÕES SOBRE EDUCAÇÃO EMPREENDEDORA NA WEB OF SCIENCE}

Na primeira fase do estudo realizou-se a pesquisa do termo entrepreneurial education, verificou-se mais de duas mil produções. Diante disso selecionou-se o período de anos para o presente estudo (2008-2017), foram então encontradas 2.474 publicações. A seguir são apresentadas as características gerais dessas publicações, de acordo com as seguintes categorias: áreas temáticas, tipo de documentos, ano das publicações, autores, título das fontes, instituições, agências financiadoras, países e idiomas, conforme determinado pela Figura 2.

\section{1 Áreas temáticas das publicações}

Na Tabela 1 apresentam-se às 10 principais áreas temáticas relacionadas ao tema, de acordo com o número de publicações. As áreas selecionadas apresentam evidências da heterogeneidade da temática.

Tabela 1 - Áreas temáticas no estudo sobre atitude empreendedora

\begin{tabular}{cc}
\hline Área temática & $\begin{array}{c}\mathbf{N}^{\circ} \text { de } \\
\text { Publicações }\end{array}$ \\
\hline $1^{\circ}$ Business economics (Economia Empresarial) & 1139 \\
$2^{\circ}$ Education educational research (Pesquisa Educacional) & 884 \\
$3^{\circ}$ Social Sciences other topics (Ciências Sociais outros tópicos) & 239 \\
$4^{\circ}$ Engineering (Engenharia) & 207 \\
$5^{\circ}$ Computer Science (Ciência da Computação) & 108
\end{tabular}


60 Public Administration (Administração Pública) 101

$7^{0}$ Psychology (Psicologia)

$8^{\circ}$ Operations Research Management Science (Pesquisa operacional, gerencial) 54

$9^{\circ}$ Environmental Sciences Ecology (Ciências ecológicas e ambientais) 46

$10^{\circ}$ Arts Humanities Other Topis (Humanidades das artes, outros tópicos) 33

Fonte: Web of Science (2018).

As principais áreas temáticas relativas às publicações sobre educação empreendedora estão relacionadas à pesquisa empresarial e educacional, com menor força destacam-se os temas ambientais e artes.

\subsection{Tipos de documentos}

A Tabela 2 apresenta os tipos de documentos referentes às publicações encontradas.

Tabela 2 - Classificação das publicações quanto ao tipo*

\begin{tabular}{cc}
\hline Tipos de publicação & Frequência \\
\hline Article & 1.217 \\
Proceedings Paper & 1.201 \\
Review & 40 \\
Editorial & 17 \\
\hline
\end{tabular}

* Algumas publicações foram classificadas em mais de um tipo, desse modo o total é superior ao número total de publicações.

Fonte: Web of Science (2018).

A maioria das publicações encontradas são artigos, seguido dos trabalhos publicados em congressos ou similares. Em menor quantidade constam as revisões e material editorial.

\subsection{Publicações por ano}

No período compreendido entre 2008 e 2017 constatou-se que o número de publicações aumentou gradativamente ao longo dos dez anos analisados, excetuando-se os anos de 2013 e 2017, em que houveram quedas, especialmente acentuada no último ano. Na Figura 3 apresenta-se a quantidade de publicações por ano.

Figura 3 - Publicações por ano

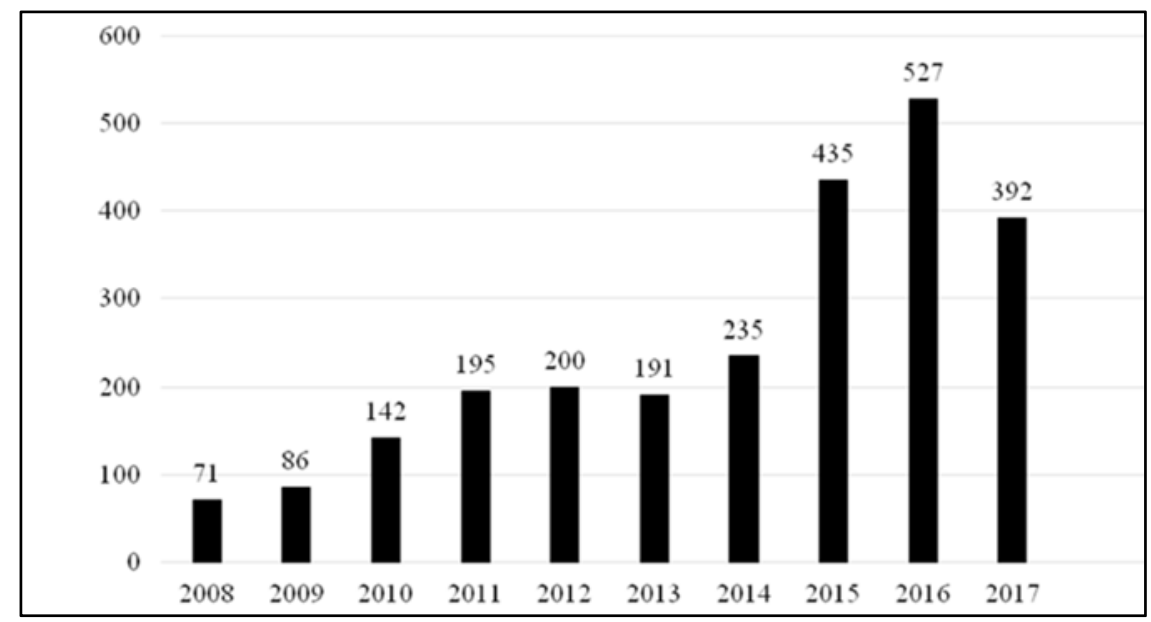

Fonte: Web of Science (2018). 
É possível observar um aumento significativo na quantidade de artigos publicados sobre educação empreendedora no período compreendido entre 2008 a 2011, no ano de 2012 praticamente permaneceram iguais o número de publicações de 2011, já em 2013 houve uma pequena queda no número de publicações em comparação ao ano anterior. Entre os anos de 2014 a 2016 é possível observar um salto na quantidade de artigos publicados, passando de 235 para 435, e em 2016 houve a máxima de publicações de todo período analisado, com um total de 527 publicações. No entanto, no ano de 2017 constatou-se uma queda significativa, com 392 artigos publicados durante o ano, 25,61\% a menos que no ano anterior.

\subsection{Principais autores}

Na Tabela 3 constam os dez autores que mais publicaram no período analisado.

Tabela 3 - Quantidade de artigos publicados por autor

\begin{tabular}{ccc}
\hline Autores & Artigos publicados & País \\
\hline $1^{\circ}$ Pihie Zal & 15 & Malásia \\
$2^{\circ}$ Bagheri A. & 13 & Irã \\
$3^{\circ}$ Markuerkiaga L. & 12 & Espanha \\
$4^{\circ}$ Urbano D. & 10 & Espanha \\
$5^{\circ}$ Errasti N. & 9 & Espanha \\
$6^{\circ}$ Kakouris A. & 9 & Grécia \\
$7^{\circ}$ Linan F. & 9 & Reino Unido e Espanha \\
$8^{\circ}$ Duval-Couetil N. & 7 & Estados Unidos \\
$9^{\circ}$ Fayolle A. & 7 & França \\
10 Guerrero M & 7 & Reino Unido \\
\hline
\end{tabular}

Fonte: Web of Science (2018).

Os principais autores são de inúmeras instituições de ensino e destacam-se nas diversas áreas de gestão. Zaidatol Akmaliah Lope Pihie é professora titular na Faculdade de Estudos Educacionais, da Universiti Putra Malaysia na Malásia, as áreas de interesse são educação empreendedora, liderança e gestão educacional, bem como metodologia de ensino. Em segundo lugar consta a professora assistente Afsaneh Bagheri, ela é a principal coautora de Pihie, e trabalha no Departamento de Desenvolvimento de Empreendedorismo, Faculdade de Empreendimento na Universidade de Teerã. Já em terceiro lugar tem-se a engenheira Leire Markuerkiaga, atualmente ela é doutoranda em Universidades Empreendedoras, na Mondragon Unibertsitatea, localizada na Espanha. As áreas de interesse de Bagheri são empreendedorismo tecnológico acadêmico, universidade empreendedora e cooperação universidade-empresa. A principal coautora de Bagheri é Errasti, a quinta autora com maior quantidade de publicações.

Pela quantidade de publicações distribuídas de forma homogênea entre os autores, percebe-se que educação empreendedora não possui um único pesquisador em evidência, pelo contrário, é pesquisada por diferentes estudiosos ao redor do mundo e que tem crescido ano após ano, ganhando impulso desde 2014, com seu ápice no ano de 2016.

\subsection{Principais Instituições e Agências Financiadoras}

Quanto às Instituições e Agências Financiadoras identificou-se heterogeneidade entre as mesmas, o que demonstra que não existe uma única instituição e/ou agência financiadora dominante. Das 2.474 publicações foram identificadas mais de 100 agências financiadoras, assim como mais de 100 instituições. Na Tabela 4 é possível verificar as instituições e agências mais destacadas. 
Tabela 4 - Principais agencias de financiamento

\begin{tabular}{cc}
\hline Agências de financiamento & Registros \\
\hline $1^{\circ}$ Economy Knowledge Department Catalan Government & 6 \\
$2^{\circ}$ Spanish Ministry of Economy Competitiveness & 6 \\
$3^{\circ}$ National Natural Science Foundation of China & 5 \\
$4{ }^{\circ}$ National Science Foundation & 4 \\
$5^{\circ}$ European Regional Development Fund & 3 \\
$6^{\circ}$ European Social Fund & 3 \\
70 European Social Fund Through Sectoral Operational Programme Human Resources Development & 3 \\
$8^{\circ}$ Russian Science Foundation & 3 \\
$9 \circ$ British Council & 2 \\
$10^{\circ}$ Dutch Ministry Of Economic Affairs10 Dutch Ministry Of Economic Affairs & 2 \\
\hline
\end{tabular}

Fonte: Web of Science (2018).

As agências de financiamento que mais apoiaram as pesquisas foram: Economy Knowledge Department Catalan Governament; Spanish Ministry of Economy Competitiveness; National Natural Science Foundation of China; National Science Foundation e European Regional Development Fund. É importante destacar que as principais agências estão localizadas na Europa, América do Norte e Ásia, e curiosamente não se tem nenhuma representação da América Latina e África.

Os países que mais publicam sobre o tema educação empreendedora são apresentados na Tabela 5.

Tabela 5 - Principais países

\begin{tabular}{|c|c|}
\hline Países & $\mathrm{N}^{\circ}$ de artigos \\
\hline $1^{\circ}$ Estados Unidos da América & 371 \\
\hline $2^{\circ}$ China & 314 \\
\hline $3^{\circ}$ Espanha & 225 \\
\hline $4^{\circ}$ Inglaterra & 202 \\
\hline 50 Romênia & 172 \\
\hline $6^{\circ}$ Alemanha & 84 \\
\hline 70 Malásia & 75 \\
\hline $8^{\circ}$ Portugal & 70 \\
\hline $9 \circ$ Austrália & 67 \\
\hline 10 Finlândia & 65 \\
\hline
\end{tabular}

Fonte: Web of Science (2018).

Quanto ao número de publicações por países (Tabela 5), os Estados Unidos da América lideram o ranking de publicações, seguido pela China, Espanha, Inglaterra e Romênia. Percebe-se que nesses países encontram-se a maior parte das instituições que possuem pesquisas relacionadas à temática. Chama a atenção a diversidade de países e suas localizações. O Brasil está em $21^{\circ}$ posição, com 36 publicações. Na Tabela 6 evidenciam-se os principais idiomas em que os trabalhos são publicados.

Tabela 6 - Principais idiomas

\begin{tabular}{|c|c|}
\hline Idioma & No de publicações \\
\hline $1^{\circ}$ Inglês & 2.311 \\
\hline 2० Espanhol & 62 \\
\hline $3^{\circ}$ Chinês & 42 \\
\hline 4o Português & 15 \\
\hline 50 Russo & 10 \\
\hline $6^{\circ}$ Alemão & 6 \\
\hline 70 Polonês & 5 \\
\hline 8० Eslovaco & 5 \\
\hline $9 \circ$ Africano & 3 \\
\hline 10 Croata & 3 \\
\hline
\end{tabular}

Fonte: Web of Science (2018). 
O idioma de destaque é a língua inglesa, que possui maior representatividade, 93,4\%. Outras línguas com menor representatividade são o chinês, espanhol e português. Diante desta pesquisa evidencia-se que o principal país que publica é os Estados Unidos da América, sendo o principal idioma o inglês, além disso, é evidente que a língua científica global é o inglês, o que foi reafirmado no estudo.

\subsection{Relatório de citações}

O relatório de citações proporciona informação estatística baseada nos resultados recuperados e informa o índice $\mathrm{h}$ (índice que utiliza por base o número de artigos publicados por um cientista e a frequência que estes artigos são citados por outros cientistas). Na Figura 4 consta o número de citações por ano.

Figura 4 - Total de citações por ano

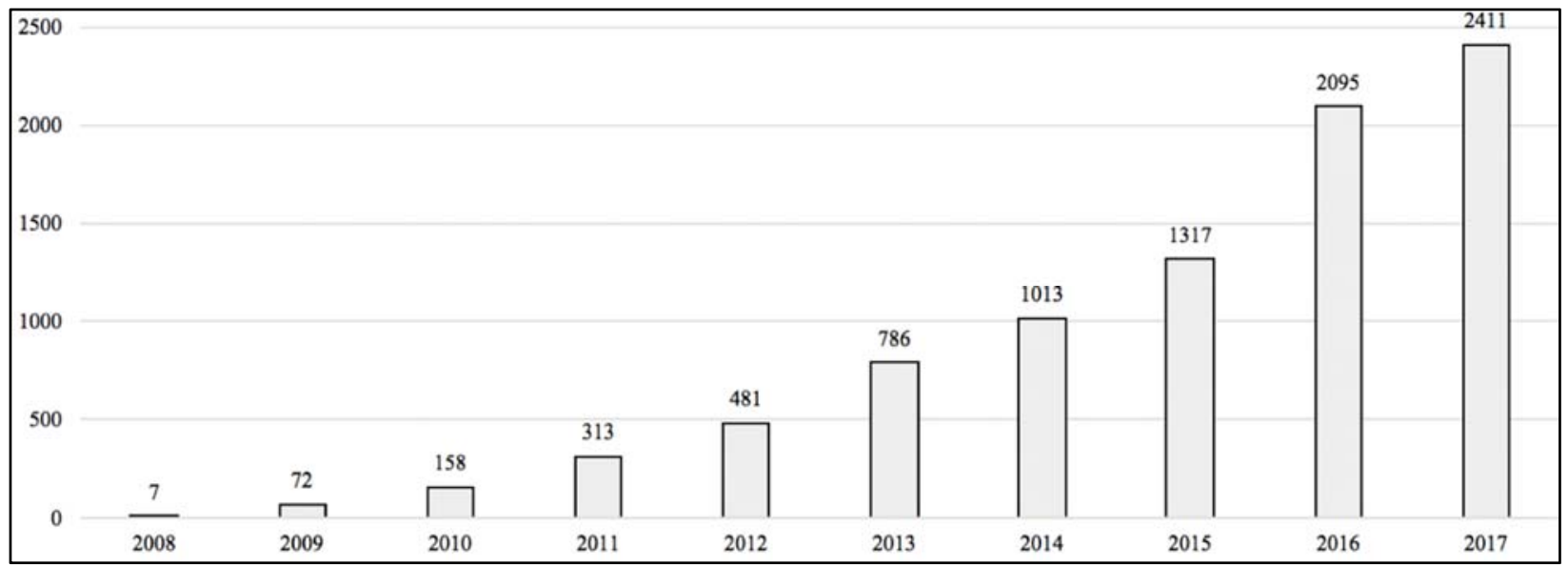

Fonte: Web of Science (2018).

O período apurado totalizou 8.653 citações, destas, 6.823 são citações sem autocitações. Mais de 6 mil artigos fizeram citação. A média de citações por item é de 3,59 e o h-index é de 44. Um índice de $h$ significa que há publicações $H$ que foram citados pelo menos $h$ vezes. Percebe-se que assim como as publicações aumentaram ano após ano, as citações também aumentaram concomitantemente.

Por meio da análise de citações identificou-se os trabalhos mais citados sobre educação empreendedora. Estes trabalhos são detalhados no Quadro 3.

Quadro 3 - Publicações mais citadas

\begin{tabular}{|c|c|c|}
\hline DESCRIÇÃO & $\begin{array}{c}\text { ANO DA } \\
\text { PUBLICAÇÃO }\end{array}$ & CITAÇÕES \\
\hline $\begin{array}{l}\text { Desenvolvimento e Aplicação Intercultural de um Instrumento } \\
\text { Específico para Medir Intenção Empreendedora } \\
\text { Por: Linan, F.; Chen, Y. } \\
\text { Onde: Entrepreneurship Theory And Practice, Volume: 33, Edição: } 3 \\
\text { Páginas: 593-617. }\end{array}$ & 2009 & 280 \\
\hline $\begin{array}{l}\text { Capital humano e sucesso empreendedor: uma revisão meta- } \\
\text { analítica } \\
\text { Por: Unger, J. M.; Rauch, A.; Frese, M.; et al. } \\
\text { Journal of Business Venturing, Volume: 26, Edição: 3, Páginas: 341-358. }\end{array}$ & 2011 & 251 \\
\hline $\begin{array}{l}\text { O impacto da educação para o empreendedorismo sobre as } \\
\text { habilidades e motivação do empreendedorismo } \\
\text { Por: Oosterbeek, H.; van Praag, M.; ljsselstein, A. } \\
\text { European Economic Review, Volume: 54, Edição: 3, Páginas: 442-454. }\end{array}$ & 2010 & 198 \\
\hline $\begin{array}{l}\text { Identificação de oportunidades e busca: o capital humano de um } \\
\text { empreendedor é importante? }\end{array}$ & 2008 & 184 \\
\hline
\end{tabular}


Por: Ucbasaran, D.; Westhead, P.; Wright, M.

Small Business Economics, Volume: 30, Edição: 2, Páginas: 153-173.

Auto-Eficiência Empreendedora: Refinando a Medida

Por: McGee, Jeffrey E.; Peterson, Mark; Mueller, Stephen L.; et al.

Entrepreneurship Theory and Practice, Volume: 33, Edição: 4, Páginas: 965-988.

Fonte: Web of Science (2018).

Dentre as publicações mais citadas constam autores que mais publicam sobre a temática como, por exemplo, Linan. Já, na Figura 5 é demonstrado o mapa de cocitações dos autores. A partir da análise de cocitação é possível analisar a estrutura intelectual entre os autores, ou seja, na análise de cocitação dos autores, quanto mais dois autores são citados juntos, mais próxima é a relação entre eles. Dessa forma, a análise de cocitação permite analisar os clusters existentes e os autores que pertencem a eles. Foram selecionados autores citados pelo menos 20 vezes.

Figura 5 - Mapa de cocitação

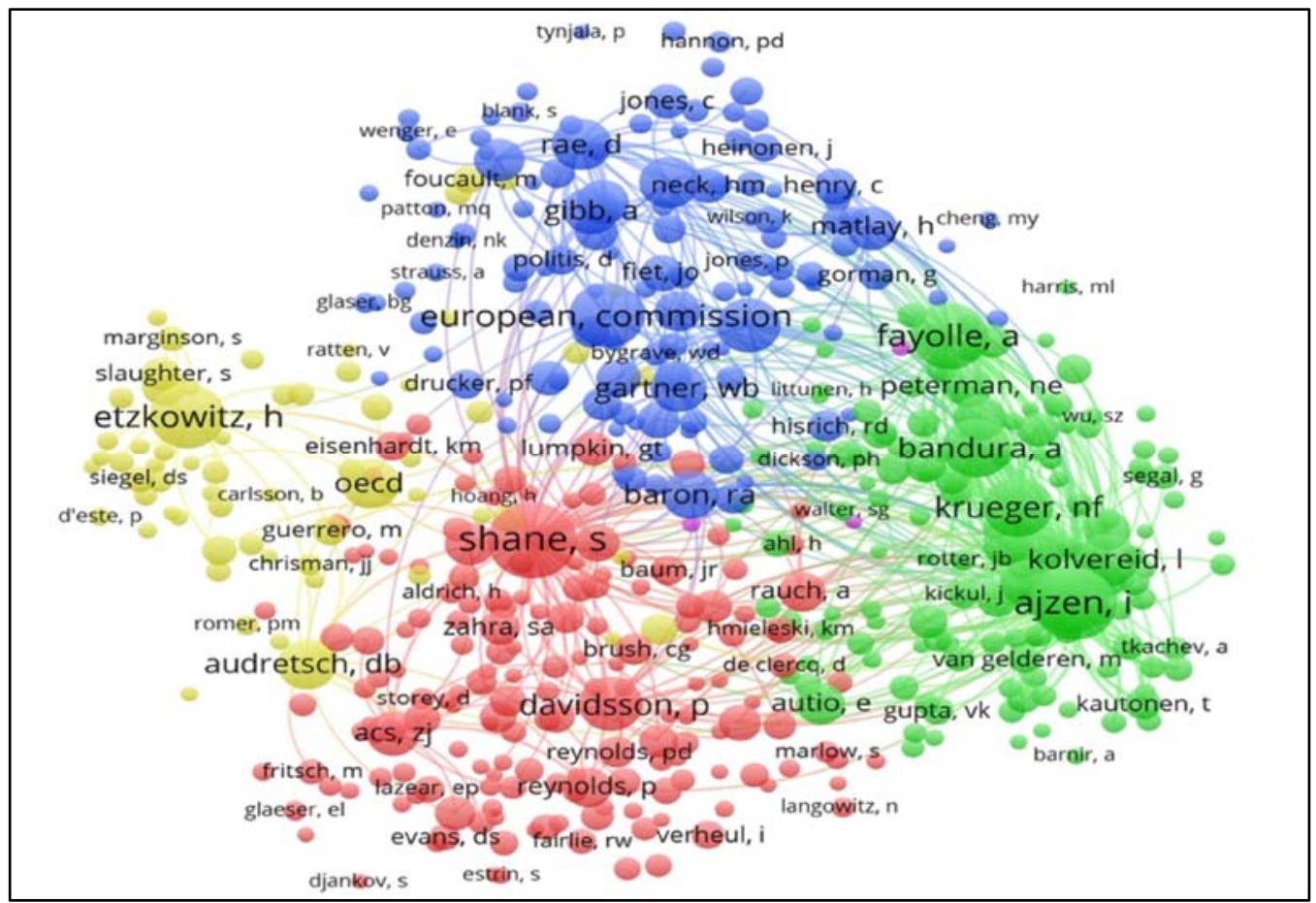

Fonte: elaborado pelos autores por meio do VOSViewer (2018).

A partir da Figura 5 notam-se 4 diferentes cores, o que configura os 4 clusters mencionados anteriormente. O maior cluster corresponde a cor vermelha, composto por referências como Shane e Davidsson, totalizando 169 itens. Em segundo lugar está o cluster verde, com 142 itens, dentre estes mencionase os autores Ajzen, Bandura, Fayolle e Krueger. Em terceira posição encontra-se o cluster em azul, composto pela Comissão Européia, Pittaway, Rae, Politis e Cope, totaliza 120 intens. O menor cluster consta em amarelo e possui 66 itens, sendo o principal Etzkowitz. Por fim, constam três itens em rosa, destes Foo e Volery não foram elencados em nenhum outro cluster apesar de terem sido citados no mínimo 20 vezes e, além destes, consta o item EC, que se acredita fazer alusão ao item Comissão Europeia, que encabeça o cluster azul, mas, por estar abreviado não foi associado pelo software. 


\subsection{Os Hot Topics relacionados com educação empreendedora}

Por intermédio do cálculo dos índices $\mathrm{h}$ e $\mathrm{m}$ é possível aferir o resultado da combinação de temas, com base principalmente no número de citações (KELLY; JENNIONS, 2006), ou seja, verificar se o tema é recente e se é um hot topic ou tem potencial de ser. Com base em uma análise prévia das publicações encontradas na Web of Science, foram selecionados 20 tópicos relacionados à temática.

Posteriormente, foi realizada a combinação de cada tópico listado na Tabela 7 com o termo entrepreneurial education, sendo calculado o total de publicações para cada combinação (tópico relacionado $\mathrm{x}$ entrepreneurial education), o h-index (índice obtido por meio do número de citações de um tópico ou combinação em determinado período, listados em ordem decrescente de citações, e é encontrado em publicações que tenham obtido um número de citações igual ou maior à sua posição no ranking) e o coeficiente $\mathrm{m}$ (obtido por meio da divisão do índice $\mathrm{h}$-b pelo período de anos que se deseja obter informações (n)).

Diante disso, na Tabela 7 estão demonstrados os resultados obtidos das combinações dos vinte temas com o tópico educação empreendedora, bem como os resultados relativos aos índices.

Tabela 7 - Hot topics no estudo sobre entrepreneurial education

\begin{tabular}{|c|c|c|c|}
\hline Área temática & $\begin{array}{c}n^{\circ} \text { de } \\
\text { publicações }\end{array}$ & $\begin{array}{c}\text { Índice } \\
\text { h-b }\end{array}$ & Índice m \\
\hline $1^{\circ}$ Entrepreneurship (Empreendedorismo) & 1.720 & 38 & 3,8 \\
\hline $\begin{array}{l}2^{\circ} \text { Education for entrepreneurship (Educação para o } \\
\text { empreendedorismo) }\end{array}$ & 1.368 & 34 & 3,4 \\
\hline $3^{\circ}$ Entrepreneurial research (Pesquisa Empresarial) & 1.248 & 32 & 3,2 \\
\hline 40 Knowledge (Conhecimento) & 775 & 28 & 2,8 \\
\hline $5^{\circ}$ Development (Cesenvolvimento) & 1.102 & 28 & 2,8 \\
\hline $6^{\circ}$ Entrepreneurial intention (Intenção Empreendedora) & 433 & 26 & 2,6 \\
\hline 7० Management (Gestão) & 524 & 25 & 2,5 \\
\hline 8० Innovation (Inovação) & 710 & 24 & 2,4 \\
\hline $9^{\circ}$ Entrepreneurial university (Universidade empreendedora) & 1.149 & 24 & 2,4 \\
\hline $10^{\circ}$ Entrepreneurial behavior (Comportamento empreendedor) & 436 & 23 & 2,3 \\
\hline $11^{\circ}$ Entrepreneurial self-efficacy (autoeficácia empreendedora) & 211 & 21 & 2,1 \\
\hline $12^{\circ}$ Entrepreneurial skills (Habilidades empreendedoras) & 662 & 20 & 2,0 \\
\hline 130 Planning (Planejamento) & 382 & 19 & 1,9 \\
\hline $14^{\circ}$ Entrepreneurial learning (Aprendizagem empreendedora) & 697 & 19 & 1,9 \\
\hline $15^{\circ}$ Social entrepreneurship (Empreendedorismo social) & 436 & 18 & 1,8 \\
\hline $16^{\circ}$ Business management (Administração de empresas) & 268 & 17 & 1,7 \\
\hline 170 Enterprise (Empreendimento) & 378 & 17 & 1,7 \\
\hline 180 Teaching (Ensino) & 492 & 14 & 1,4 \\
\hline $19^{\circ}$ Creativity (Criatividade) & 178 & 9 & 0,9 \\
\hline $20^{\circ}$ Achievement (Realização) & 114 & 8 & 0,8 \\
\hline
\end{tabular}

Fonte: Web of Science (2018).

Orientando-se pelas considerações de Banks (2010) pode-se classificar como hot topics, ou tópicos quentes, as combinações de entrepreneurship education (educação empreendedora) com os termos que obtiveram índice m superior a 2, ou seja, 11 termos. Dentre estes destaca-se os tópicos: Empreendedorismo, Educação para o empreendedorismo e Pesquisa empresarial. Já os demais termos obtiveram m entre 0,5 e 2, o que significa que apresentam grande potencial de se tornarem um tópico quente. A partir desta análise é possível afirmar que a temática educação empreendedora é um hot topic (BANKS, 2010). 


\subsection{Mapa Textual}

Por meio da análise das palavras-chave dos 2.474 artigos, 84 palavras foram utilizadas com maior frequência. Na Figura 6 elaborou-se uma rede com as palavras-chave mais adotadas. Na rede verificam-se seis clusters predominantes, o principal corresponde às palavras elencadas no grupo Empreendedorismo (em vermelho), em seguida Educação (em verde) e, por conseguinte, Educação Empreendedora (em azul), neste último o termo educação empreendedora é coberto pelo termo empreendedorismo. As ligações totalizam 2.386 links. Além destes, foram elencados mais três clusters, sendo amarelo, rosa e azul claro, que apresentam menor quantidade de itens.

Figura 6 - Rede de palavras

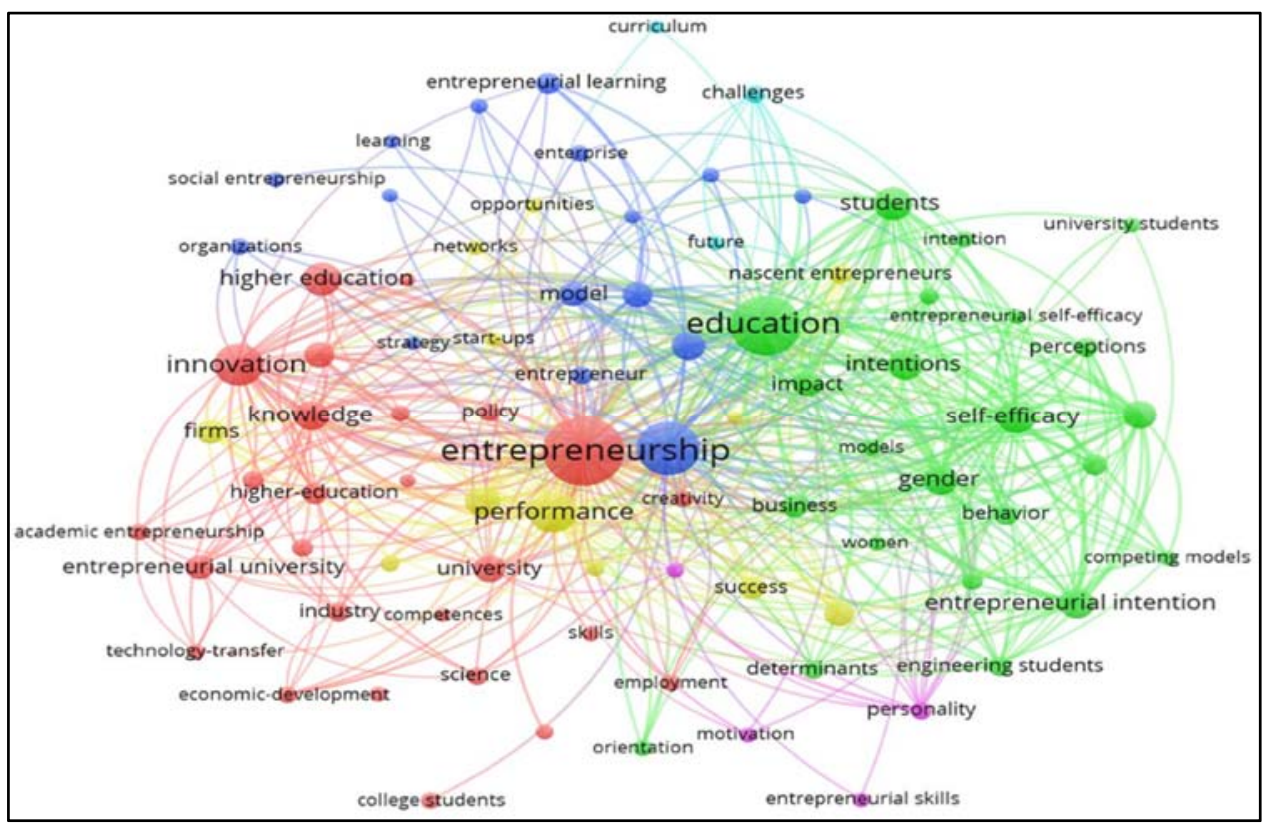

Fonte: elaborado pelos autores (2018).

Observa-se o cluster com a palavra empreendedorismo (em vermelho) como o principal expoente, outro com a palavra educação e um terceiro cluster com a palavra educação empreendedora. Do cluster empreendedorismo surge um novo cluster com a palavra inovação onde nele estão contidos os termos educação superior, conhecimento, universidade empreendedora e empreendedorismo acadêmico.

Na Figura 7 mostra-se um diagrama de densidade dessa rede de palavras-chave, cujas cores são similares a de um gráfico térmico. 
Figura 7 - Diagrama de densidade de palavras-chave

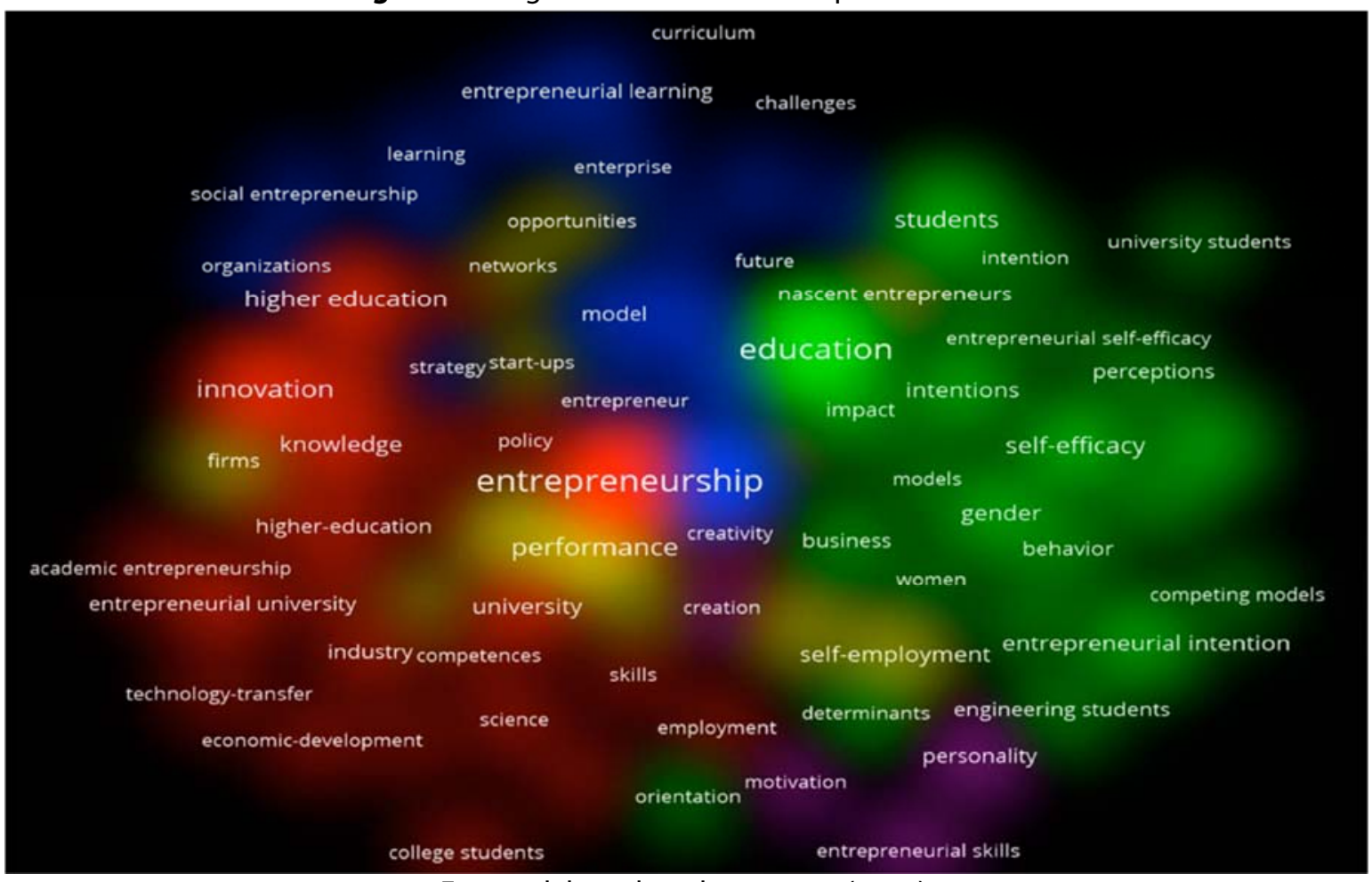

Fonte: elaborado pelos autores (2018).

Dentre as principais palavras ligadas à educação empreendedora, a palavra empreendedorismo apresenta maior influência (Figura 7).

\section{CONSIDERAÇÕES FINAIS}

O objetivo desse estudo foi apresentar o cenário das pesquisas na área de educação empreendedora na base de dados Web of Science, incluindo a caracterização da produção, dos aspectos metodológicos e dos temas correlatos. Entende-se que o empreendedor não pode ser apenas entendido como uma pessoa que nasce com vocação para empreender, mas sim como um indivíduo que possui um conjunto de características que o levam a ser empreendedor, e estas características podem ser aprendidas.

Diante disso, a formação de empreendedores torna-se um importante fator para o desenvolvimento econômico de uma região, tornando-a alavanca de negócios inovadores e formadora de capital social com elevado nível de conhecimento. A partir do estudo, pode-se perceber a importância da educação empreendedora nas pesquisas recentes. A partir destas constatações, observa-se a necessidade das organizações governamentais e das instituições de ensino atentarem-se para a oportunidade de contemplar uma educação rumo ao empreendedorismo, visando a formação de indivíduos com este potencial. Espera-se estabelecer um ambiente propício ao desenvolvimento do empreendedorismo.

A análise das publicações sobre educação empreendedora na base de dados Web of Science, evidenciou 2.474 publicações relacionadas ao tema, ou seja, esta é a população da pesquisa, às áreas temáticas principais foram economia empresarial, pesquisa educacional e engenharia. Salienta-se que ao longo do trabalho, a partir da população total, serão analisados diferentes temáticas, enfatizando, sempre, as produções predominantes, o que pode variar dependendo da temática pesquisada.

O presente estudo não contempla uma amostra, mas a totalidade de publicações, analisando os aspectos quantitativos. Constatou-se que a maioria das publicações são artigos, sendo que no período de 2008 a 2017 a produção científica relacionada ao tema aumentou gradativamente ao longo dos dez anos analisados, ganhando impulso a partir de 2014, sendo o ano de 2016 o boom, em que o tema educação empreendedora 
ganhou destaque em diferentes meios acadêmicos. Já, no ano seguinte, em 2017, houve um retrocesso de publicações de aproximadamente $26 \%$ diante do ano anterior.

Estudos de natureza bibliométrica buscam ampliar a compreensão de um tema emergente, como a educação empreendedora. Além disso, servem para demonstrar características vinculadas à produção científica, verificar os países e instituições que se destacam e relacionar os estudos desenvolvidos no contexto brasileiro com o internacional, percebendo assimetrias ou convergências.

No decorrer do trabalho percebeu-se a utilidade de mecanismos de busca como o Web of Science para a realização de pesquisas acadêmicas, que servem de ferramenta para que a comunidade acadêmica tenha acesso às publicações, assim como se busque demais informações a respeito da evolução dos temas de interesse. Os resultados dessa pesquisa evidenciam que a educação empreendedora representa um hot topic, e mesmo diante da queda de publicações de 2016 a 2017 ainda é um tema em destaque, uma oportunidade para pesquisadores do empreendedorismo, comportamento empreendedor e educação.

Salienta-se por meio dos artigos mais citados que a educação empreendedora tem sido tema de pesquisa e estudo nos últimos anos, sendo apontada como estratégia para a promoção e disseminação do empreendedorismo. Por meio do ensino-aprendizagem este importante papel tem sido desenvolvido, contribuindo para formação e o despertar não só de novos empreendedores, mas também de indivíduos impactados de forma positiva frente ao desenvolvimento e crescimento econômico e social, como a promoção das organizações nas quais estão inseridos.

Como limitação do estudo, cita-se a sua superficialidade, sugere-se que estudos futuros desta natureza possuam uma maior profundidade, contemplado e comparando a fundo metodologias distintas adotadas, assim como a base teórica dos diferentes autores.

\section{REFERÊNCIAS}

BAKAR, R.; ISLAM, M. A.; LEE, J. Entrepreneurship Education: experiences in selected countries. International Education Studies, v. 8, n. 1, p. 88-99, 2015.

BANKS, M. G. An extension of the hirsch index: indexing scientific topics and compounds. Scientometrics, Vol. 69, No. 1, 161-168, 2006.

BAR-ILAN, J. Which h-index? - A comparison of WoS, Scopus and Google Scholar. Scientometrics, v. 74, n. 2, p. 257-271, 2008.

BELFORT, A. C.; FREITAS, H. M. R. de.; MARTENS, C. D. P. Affordances em Tecnologia Móvel: um tema já consolidado ou uma tendência? In: SEMINÁRIOS EM ADMINISTRAÇÃO, 18., 2015, São Paulo. Anais do XVIII SEMEAD Seminários em Administração. São Paulo: USP, 2015. p. 1-16.

CAPES. Acesso à informação CAPES. Disponível em: < http://www.capes.gov.br/>. Acesso em: 14 out. 2017.

COMISSÃO EUROPEIA. Rethinking education: investing in skills for better socio-economic outcomes. 2012. Disponível em: < https://ec.europa.eu/europeaid/rethinking-education-investing-skills-better-socioeconomic-outcomes-com2012-669_en >. Acesso em: 21 nov. 2017.

DOLABELA, F. C. O segredo de Luísa: uma ideia, uma paixão e um plano de negócios. 30. ed. São Paulo: Casa de Cultura, 2006.

DOLABELA, F. C. Oficina do empreendedor: a metodologia do ensino que ajuda a transformar conhecimento em riqueza. Rio de Janeiro: Sextante, 2008.

DOLABELA, F.; FILION, L. J. Fazendo revolução no Brasil: a introdução da pedagogia empreendedora nos estágios iniciais da educação. Revista de Empreendedorismo e Gestão de Pequenas Empresas, v. 3, n. 2, p. 134-181, 2013. 
DORNELAS, J. C. A. Empreendedorismo: transformando ideias em negócios. 3. ed. Rio de Janeiro: Elsevier, 2008.

DRUCKER, P. F. Inovação e espírito empreendedor: prática e princípios. 6. ed. São Paulo: Pioneira, 1996.

EUROPEAN COMMISSION ENTERPRISE AND INDUSTRY DIRECTORATE-GENERAL. Entrepreneurship in higher education, especially in non-business studies: final report of the expert group. European Commission, March, 2008. Disponível em: <https://ec.europa.eu/growth/content/final-report-expert-group-entrepreneurshiphigher-education-especially-within-non-business-0_en>. Acesso em: 14 dez. 2017.

FAYOLLE, A.; GAILLY, B. The impact of entrepreneurship education on entrepreneurial attitudes and intention: hysteresis and persistence. Journal of small business management, v. 53, n. 1, p. 75-93, 2015.

FILION, L. J. Diferenças entre sistemas gerenciais de empreendedores e operadores de pequenos negócios. Revista de Administração de Empresas - RAE, São Paulo, v. 39, n. 4, p. 6-20, out./dez. 1999.

FRANCESCHET, M. A. Comparison of bibliometric indicators for computer science scholars and journals on Web of Science and Google Scholar. Scientometrics, v. 83, n. 1, 243-258, 2010.

GEM. Global Entrepreneurship Monitor. Empreendedorismo no Brasil. 2010. Simara Maria de Souza Silveira Greco et al. Curitiba: IBQP, 2010.

GEM. Global Entrepreneurship Monitor. Empreendedorismo no Brasil. Relatório Executivo. 2015. Coordenação de Simara Maria de Souza Silveira Greco. Autores: Mariano de Matos Macedo... [et al]. Curitiba: IBQP, 2014.

GERBER, M. E. Empreender: fazendo a diferença. São Paulo: Fundamento Educacional, 2004.

GOMES, D. C.; SILVA, L. A. F. Educação empreendedora no ensino profissional: desafios e experiências numa instituição de ensino. HOLOS, Natal, v. 1, n. 34, p. 118-139, 2018.

HAIR JR, J. F. Fundamentos de métodos de pesquisa em administração. Porto Alegre: Bookmen, 2005.

HANDRIMURTJAHJO, A. D.; SETIADI, N. J.; KUNCORO, E. The role of entrepreneurship rducation in forming students' entrepreneurial attitudes. Advanced science letters. v. 21, n. 4, p. 596-600, 2015.

HIRSCH, J. E. An index to quantify an individual's scientifi c research output. Proceedings of the National Academy of Sciences of the United States of America, v. 102, n 46, p. 16569-16572, 2005.

KELLY, C. D.; JENNIONS, M. D. The $h$ index and career assessment by numbers. Trends in Ecology and Evolution, v. 21, n. 4, p. 167-170, 2006.

KATZ, J. A. The chronology and intellectual trajectory of American entrepreneurship education 1876-1999. Journal of Business Venturing, New York, v. 18, n. 2, p. 283-300, 2003.

KLEIN, A. Z.; SILVA, L. V.; MACHADO, L. Metodologia de pesquisa em administração: uma abordagem prática. São Paulo: Atlas, 2015.

KLEIN, P.; BULLOCK, J. B. Can entrepreneurship be taught? Journal of Agricultural and Applied Economics, v. 38, n. 2, p. 429-439, 2006.

KRAKAUER, P. V. C. et al. Ensino de empreendedorismo: utilização do business model generation. Revista de Administração e Inovação, São Paulo, v. 12, n.1, p. 7-23, jan./mar. 2015.

LIMA, E. et al. Oportunities to improve entrepreneurship education: contributions considering Brazilian Challenges. Journal of Small Business Management, v. 53, n. 4, p. 1033-105, 2015. 
LIMA, E. et al. Educação superior em empreendedorismo e intenções empreendedoras dos estudantes: relatório do estudo. São Paulo: Grupo APOE. 2014.

LOPES, C. L. J. Educação empreendedora: um estudo do projeto de empreendedorismo 10.0 aplicado aos alunos do curso técnico em informática. Revista de Empreendedorismo, inovação e tecnologia, v. 1, n. 1, p. 39-44, 2014.

MCCLELLAND, D. C. Characteristics of successful entrepreneurs. The Journal or Creative Behavior, v. 21 , n. 3. p. 219-233, 1987.

MOREIRA, H. S. A.; MOREIRA, M. A.; SILVA, W. A. C. Dez anos de pesquisa em empreendedorismo apresentados nos enanpads de 2003 a 2012: análise dos autores engajados na área. REGEPE, São Paulo, v. 3, n. 1, p. 33-45, 2014.

MORETTI, S. L. A.; CAMPANÁRIO, M. A. A produção intelectual brasileira em responsabilidade social empresarial - RSE sob a ótica da bibliometria. Revista de administração contemporânea, Rio de Janeiro, $v$. 13, n. 8, p. 68-86, 2009.

POLITIS, D. The process of entrepreneurial learning: a conceptual framework. Entrepreneurship Theory and Practice. v. 29, n. 4, p. 399-424, 2005.

PORTELA, J. et al. Microempreendedorismo em Portugal: Experiências e Perspectivas. Lisboa: INSCOOP, 2008.

RICHARDSON, R. J. Pesquisa social: métodos e técnicas. São Paulo: Atlas, 2011.

ROESCH, S. M. A. Projetos de estágio e de pesquisa em administração. 3. ed. São Paulo: Atlas, 2005.

SCHAEFER, R.; MINELLO I. F. A Formação de novos empreendedores: natureza da aprendizagem e educação. Revista da Micro e Pequena Empresa FACCAMP, Campo Limpo Paulista, v. 11, n. 3 p. 2-20, 2017.

SCHAEFER, R.; MINELLO I. F. Educação empreendedora: premissas, objetivos e metodologias. Revista Pensamento Contemporâneo em Administração, Rio de Janeiro. v. 10, n. 3, p. 60-81, jul./set. 2016.

SCHUMPETER, J. A. A Teoria do Desenvolvimento Econômico: uma investigação sobre lucros, capital, crédito, juro e o ciclo econômico. Tradução de Maria Sílvia Possas. Rio de Janeiro: Nova Cultural, 1985.

SILVA, J. F.; PENA, M. P. R. O. Bê-á-bá do ensino em empreendedorismo: uma Revisão da literatura sobre os métodos e práticas da educação empreendedora. Revista de Empreendedorismo e Gestão de Pequenas Empresas, v. 6, n. 2, p. 372-401, mai/ago. 2017.

SOUZA, E. C. L. et al. Métodos e técnicas de ensino e recursos didáticos para o ensino do empreendedorismo em IES brasileiras. In: SOUZA, E. C. L.; GUIMARÃES, T. A. (Org.). Empreendedorismo além do plano de negócio. São Paulo: Atlas: 2006. p. 241-259.

TAVARES, C. M.; MOURA, G. L. de; ALVES, J. N. Educação empreendedora e a geração de novos negócios. Observatorio de la Economía Latinoamericana, n. 188, p. 1-8, 2013.

TRIVIÑOS, A. N. S. Introdução à pesquisa em ciências sociais: a pesquisa qualitativa em educação. São Paulo: Atlas, 2008.

UNCTAD SECRETARIAT. Division on investment and enterprise: results and impact - Report 2015, United Nations Conference on Trade and Development (UNCTAD), Genebra. Disponível em: <http://unctad.org/en/PublicationsLibrary/diae2015d1_en.pdf> Acesso em: 20 fev. de 2017.

VEIGA, C. Espírito santo empreendedor. Vitória: Sebrae, 2006. 
VIEIRA, S. F. A. et al. A visão dos estudantes universitários de administração sobre empreendedorismo: comparações entre o Estudo Guess Brasil 2011 com o levantamento realizado na Universidade Estadual de Londrina- PR. Revista de Empreendedorismo e Gestão de Pequenas Empresas, v. 3, n. 3, p. 77-103, 2014.

VOLKMANN, C. Entrepreneurship studies: an ascending academic discipline in the twenty-first century. Higher Education in Europe, v. 29, n. 2, p. 177-185, 2004.

ZAMPIER, M. A.; TAKAHASHI, A. R. W. Competências e aprendizagem empreendedora em MPE's educacionais. Revista Pensamento Contemporâneo em Administração. v. 8, n. 3, p. 1-22, 2014. 